\title{
Aligning BIM with FM: Streamlining the Process for Future Projects
}

Colleen Kasprzak and Craig Dubler, (The Pennsylvania State University, USA)

\begin{abstract}
A study performed by the National Institute of Standards and Technology (NIST), USA in 2004 found that owners account for approximately $\$ 10.6$ billion of the $\$ 15.8$ billion total inadequate interoperability costs of U.S. capital facility projects in 2002 . Because of these inefficiency costs, it becomes vital that information produced during the design and construction phases of a project be transferred into operations with maximum leverage to the end users. However, very few owners have defined these informational needs or developed an integration strategy into existing maintenance management systems. To increase operational efficiency, an organization must first develop an understanding of their operating systems, as well as identify how Building Information Modeling (BIM) will add value to their daily tasks.

The Pennsylvania State University (PSU) has a unique opportunity to diversely implement BIM processes because not only does the University act as an owner, but also as designer and construction manager on the majority of projects. The struggle that PSU faces is one that is unique only to owners with a large, existing, multifaceted building inventory. This paper outlines the current initiative by the Office of Physical Plant (OPP), the asset manager at PSU, to develop an information exchange framework between BIM and FM applications to be used internally. As a result of this research, PSU has been able to define owner operational requirements for future projects and develop a flexible integration framework to support additional BIM tasks and information exchanges.
\end{abstract}

Keywords: Building Information Modeling, Facility Management, Owner, Processes

\section{Introduction}

According to The Smart Market Report produced by McGraw-Hill in 2008, owner organizations are beginning to see that the value of BIM implementation goes beyond the design and construction of a facility, having the potential to integrate within their operational work flows. This document indicates that $41 \%$ of the owners reported that BIM has a positive impact on their projects (McGraw-Hill 2008). Additionally, one-third are very willing to purchase BIM software for other team members, and half are at least moderately willing to expend resources for the extra for time and effort required when detailing BIM models. However, owners currently have limited opportunities to use BIM for operations and maintenance purposes. As those capabilities develop; BIM uses within owner organizations could increase significantly.

Owner organizations are struggling to calculate the amount of savings available through the implementation of BIM during the lifecycle of a facility. According to a study performed by NIST (Gallaher et al. 2004), owners incur approximately $\$ 10.6$ billion of the total inadequate interoperability costs of U.S. capital facility projects ( $\$ 15.8$ billion in 2002). It is vital that information developed in the design and construction phases is transferred into operations with maximum benefit to the owners. The overall impact of O\&M is two times the amount of time spent on preventative maintenance, and four times the amount of time on corrective maintenance over a 25 year period. Therefore, if accurate information is not documented at 
the end of the construction phase, it has an exponential adverse effect on the facility performance level.

Through initial research, it has been determined that very few owners have defined their actual needs and how this information can be leveraged in their management systems, the level of detail necessary to maintain information efficiency, and how data developed during the project can be integrated into their facility management systems. To increase the operational efficiency, an organization must first develop an understanding of their operating systems and identify how Building Information Modeling (BIM) can add value to their day to day activities. Owners need to play an integral role in the information flow throughout the lifecycle of a building project.

\section{Research Aim and Objectives}

The purpose of this research is to develop a flexible integration framework to support information exchanges between building information models and existing facilities management applications. In doing so, the following objectives will be met: identify current challenges facing the integration of BIM into existing facility management processes; test and validate the current software capabilities for BIM to facility management integration; document lessons learned to produce facility information throughout the project lifecycle; and increase quality and quantity of facility information prior to project turnover. By developing a strategic implementation plan for the information exchange process between project stakeholders, the goal is to develop a single point, bidirectional database for documenting asset lifecycle information for future facility projects.

\section{Background}

The Pennsylvania State University (PSU) is a land grant university and public research institution. While deeply rooted in tradition, the University is determined to remain on the cutting edge of knowledge and technology. One of the major goals of the University is to generate, disseminate, and integrate relevant and valuable knowledge to major industries.

PSU owns an extensive, multifaceted building inventory over nineteen campuses throughout the state of Pennsylvania. The University has 1,718 buildings over 2,000 gross square foot (GSF), with the University Park campus containing 933 buildings. The University Park campus has a total of 20 million GSF which is valued at $\$ 5$ billion. The Office of Physical Plant (OPP) supports and maintains the University Park campus, as well as is involved with the design and construction on new projects, major and minor renovations, rehabilitations, and major maintenance work. Due to the magnitude of the campus building inventory, there is a backlog of major maintenance projects valued at over $\$ 2.6$ billion. While the OPP saw some benefit of using BIM on recent design and construction projects on PSU campuses, the idea of implementing an overall BIM strategy seemed incomprehensible when considering the amount of effort and resources needed to just complete the backlog of projects, without modeling or associating the appropriate data to the existing facilities and assets. However, due to the advanced systems and processes in place and the overall technological capabilities of the OPP, a strategy is currently being developed to streamline the processes between the facility project lifecycle and the operations of that facility.

\section{Current Information Exchange Processes within Penn State}

The OPP currently employs 1400 personnel in eleven different departments. For the purpose of this research, the focus will be on streamlining the information exchanges between outside consultants, the OPP Work Control Center, and the OPP Design and Construction department. OPP Design and Construction provides a multitude of services to all of the PSU campuses, which include architectural and engineering services, construction and project management, construction administration, as well as maintaining the University's archival library for all facilities on all PSU campuses. The OPP has a unique opportunity to diversely

Kasprzak, C and Dubler, C (2012) 'Aligning BIM with FM: streamlining the process for future projects', Australasian Journal of Construction Economics and Building, 12 (4) 68-77 
implement information exchange processes because not only do they act as an owner, but as both the professional and construction manager on the majority of university projects. Due to this position, the OPP has the ability to research, test, and create processes which allow for an uninterrupted flow of information beginning at project conception.

\section{Current BIM Implementation}

The OPP has required the use of BIM on new construction and renovation projects valuing over $\$ 5$ million, as well as any other projects reviewed and categorized as appropriate by the project manager. The documents developed contain not only the minimum BIM Use requirements (Design Authoring, Design Review, 3D Design Coordination, Constructability Reviews, 3D Construction Coordination, and Record Modeling), but the information and data requirements for optimal use in operations (Dubler et all 2010). Using the recommended processes and templates from the BIM Project Execution Planning Guide (CIC 2009), the OPP has developed a strategy to stimulate collaboration, communication, and coordination by all project stakeholders in the early phases of a building project.

On the PSU University Park campus the OPP is typically the end operator of a facility, not the end user. Because of this, those involved with the majority of the operational tasks of all newly proposed facilities participate not only in the development of specific facility maintenance data requirements, but also the development of the facility design. The OPP sees a benefit in communicating these needs by refocusing some of the effort during the early stages of a project to designing for maintenance. The purpose of this exercise is to assist the OPP Work Control Center in receiving the facility and asset data for commissioning and maintenance tasks, as well as develop an environment which is optimal for the lifecycle of the facility.

\section{OPP Work Control Center}

The OPP Work Control Center (WCC) plans; prioritizes, and plans all maintenance, repair, and renovation work at the University Park Campus. Using a web-based customer information system, the WCC manages the work reception function and receives customer work requests. The WCC is also responsible for developing and managing all major maintenance projects, as well as the Capital Renewal program, performing facility audits and building inspections. The FM application implemented by the WCC is an Enterprise Asset Management (EAM) system. The EAM system maintains over 50,000 mechanical and electrical assets electronically, requiring all maintenance personnel to use PDA's, tablets, or lap tops when assessing and completing preventative, corrective, emergency, or requested maintenance work orders.

\section{Gaps in Workflows}

A recent gap analysis of the current maintenance management process reflected an environment that included the following:

- Departmental barriers which inhibit information, product and process sharing

- The creation, purchase, and maintenance of a significant amount of software to manage all assets differently, resulting in a duplication of effort with no added value and issues with application interoperability

- An inability to determine incurred maintenance costs when work orders are not written against an asset, facility, or location, but by project account

- Global corporate policies which are enforced without consideration of cost or administrative burden

- A dependency on "tribal knowledge" due to a low percentage of personnel turnover rate. 
A change of process is necessary to be proactive as a large owner. Best practices for operations are achievable when processes and information are exchanged seamlessly cross departmentally. The gap analysis recommended an upgrade of the existing EAM system, using the developed functional information hierarchy developed by the vendor. Not only would this eliminate several custom programs between departments, but give the OPP and the WCC the ability to reform their current workflows and develop a sound maintenance strategy.

As shown in Table 1, the WCC has a significant amount of work orders to complete annually. The process proposed suggests that if the OPP and WCC can eliminate ten percent of the time a service engineer or maintenance personnel spends on a typical work order; there will be a significant amount of savings of $\$ 2.2$ million annually.

Although there are obvious gaps between information workflows within the OPP, it is also important to note that this integration includes all initial project stakeholders. Professionals, engineers, consultants, and contractors need to recognize that they are also responsible for providing much of the operational data which is required to run a facility efficiently. Collaboration between all parties is needed to produce a seamless information exchange between design, construction, building commissioning, project turnover, to initial operations.

\begin{tabular}{|c|c|c|c|c|c|}
\hline \multicolumn{4}{|c|}{ FY 2009/2010 WCC Work Orders } & \multicolumn{2}{|c|}{ Projected Savings } \\
\hline Type & Amount & Time (hrs) & Average Wage & Time $(\min )^{*}$ & Monetary \\
\hline $\begin{array}{l}\text { Preventative } \\
\text { Maintenance }\end{array}$ & 109,000 & 1.5 & $\$ 50.00 / \mathrm{hr}$ & 45 & $\$ 817,500$ \\
\hline $\begin{array}{l}\text { Corrective and } \\
\text { Emergency Maintenance }\end{array}$ & 55,000 & 5 & $\$ 50.00 / \mathrm{hr}$ & 45 & $\$ 1,375,000$ \\
\hline Total & 164,000 & 438,000 & $N / A$ & 45 & $\$ 2,200,000$ \\
\hline
\end{tabular}

Table 1 Projected Cost Savings for Completed Work Orders

\section{Industry Standards for BIM to FM}

When faced with the challenge of BIM implementation in the operations phase, there are very few examples of success. One reason for the lack of success is that owner organizations have spent many years developing and refining their operation processes, and current BIM deliverables do not align with their standardized objectives (Bernstein and Pittman, 2004). Therefore, there is an interoperable gap that must encompass the operations phase, allowing the owner to be a key team member. To increase operational efficiency, an organization must first develop an understanding of the operational systems inside their organization, and how BIM can add value to their day to day activities.

\section{Current Industry Case Studies of BIM to FM Integration}

There have been several recent efforts to develop an integrated information platform into the operations phase of a facility. The Sydney Opera House FM Exemplar Project (Ballesty 2006 ) used BIM to link key performance indicators to support the total asset management (TAM) system for the project after construction. Additionally, the School of Cinematic Arts (SCA) at the University of Southern California (USC) may well be the first project to implement BIM throughout the full lifecycle of a project in the U.S. (Smith 2009). The SCA project, which was funded mostly by the Lucasfilm Foundation, utilized an integrated project delivery (IPD) to keep the owner's interest in mind throughout the design and construction of the facility. Specifically, this project attempted to use BIM to monitor the heating, air conditioning and electrical systems in the building (Becerik-Gerber, Rice 2010). Finally, and 
more recently, the General Services Administration (GSA) and NASA are joining together to integrate BIM for facility management on the NASA Langley Research Center (LaRC). The objective of this endeavor is to prove that an integration between the models developed in construction NASA's computerized maintenance management system (CMMS) is possible and valuable. These recent projects are pushing the envelope in BIM to FM integration, and should be considered when developing owner organization standards.

\section{The Construction Operations Building Information Exchange (COBie)}

The Construction Operations Building Information Exchange (COBie) was developed by the United States Army Corps of Engineers (USACE). This approach consists of several different parties capturing facility data during the entire project lifecycle, not solely at project turnover. COBie has been designed as an open format standard, implementing IFCs in order to be interoperable with several different types of software. All project stakeholders have the ability to import and export specific facility data during the project through a central database.

In March 2010 at the National Facility Management \& Technology Trade Show COBie Challenge, certain software vendors were called upon to demonstrate the information integration capabilities of their product in relation to their supported business life-cycle workflows using COBie2. The teams had to qualify based on a set of previously identified quality criteria, participate in a public interoperability demonstration, as well as engage in follow-up testing of their software. All vendors involved successfully completed the challenge (East 2010). The purpose of the COBie Challenge is for software vendors to prove their successful integration from construction to operations.

\section{Challenges}

Many of the current projects that are using BIM across a facility management platform are being driven by the contractors and do not keep the owner's interest in mind throughout the facility lifecycle. In order to maximize the benefit of integration in the operations phase, the information should be pulled from the project team using owner guidelines (Dubler, Messner, and Anumba 2010). The projects that have maintained the interest of the owner throughout the project lifecycle (Sydney Opera House and SCA) have provided great examples of success, but little detail on how to achieve the success.

Information exchange from construction to operations is not a seamless process. The 2010 COBie Challenge proves that interoperability between certain software and COBie2 is possible; however, some vendors are considerably more advanced in their integration than others. End users of this information exchange need to recognize that resources will be spent on manually adjusting, exporting, and importing COBie data into their existing FM system. COBie2 allows for the addition or customization of data to support specific project requirements of an owner or facility, but only with a select few of software programs. It is not yet capable to integrate effortlessly into an existing and extensive FM database, much like that of PSU, without expending a significant amount of resources. Therefore, many owners are developing standard operations internally and testing them through pilot projects. In order to move forward in the development of full facility management integration, the efforts being produced by separate owners should be shared and standardized.

\section{Research Methodology}

BIM has the ability to benefit many sectors within an owner organization, although the challenge exists of where to start (CRC 2007). The focal point for this research is to streamline the information exchange process during the project lifecycle into operations of the facility. The following research steps, stated below and represented in Figure 2, were conducted to develop the concepts addressed in this paper: 
1. Perform literature review of previous studies and ongoing owner initiatives

2. Identify the need for BIM to FM integration within the OPP

3. Analyze existing FM systems and workflows

4. Conduct expert interviews with the Work Control Center

5. Organize focus group meeting with OPP and vendors

6. Develop a strategy for BIM to FM Integration with the OPP

7. Test and validate strategy with industry feedback and pilot project

In order to develop an appropriate BIM to FM integration strategy for an owner of this magnitude, it was necessary to review several other owner BIM initiatives including USACE, the Sandia National Research Laboratory, the University of Indiana, Target, and Crate \& Barrel. Upon review of these industry initiatives, it was apparent that there was little to no research completed regarding a direct link between the PSU selected BIM platform and the existing EAM system. After further investigation and analysis of the current workflows and processes within the OPP, several expert interviews and an analysis of the current systems was performed within the WCC in order to determine the gaps, challenges, and benefits for a full BIM to FM integration.

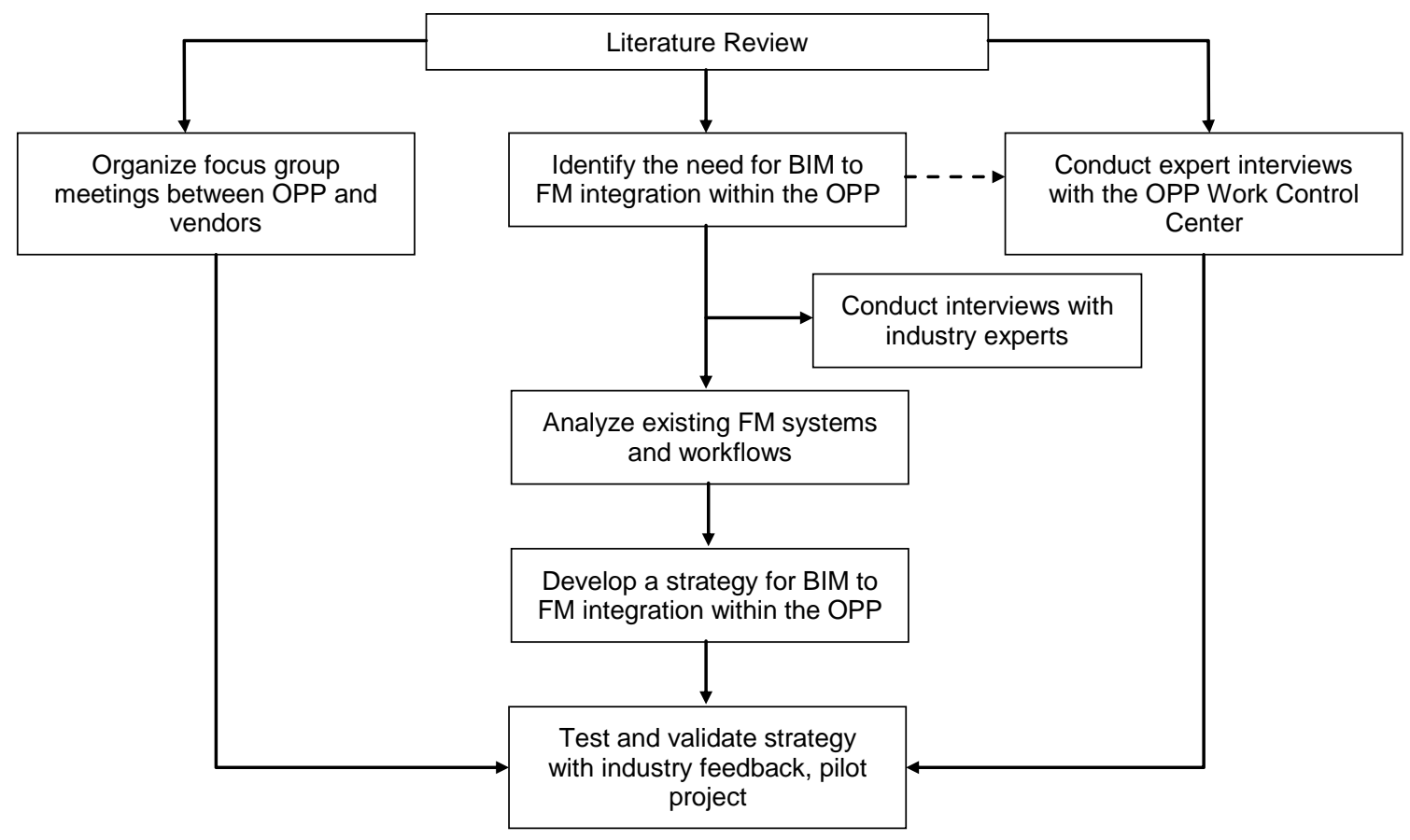

Figure 1 Research Methodology Workflow Process Maps

A focus group was then formed to develop the direct integration. This group consisted of three members of the OPP, two members of the Computer Integrated Construction (CIC) Research Group, a contractor, as well as several vendor representatives and support from each platform. Together this team began to develop a strategy for a direct link between BIM to the existing EAM system and identified a pilot project on the University Park campus to implement the developed protocol. The testing and validation process is ongoing and will produce a field tested study of a direct integration between BIM and FM processes one month following facility turnover.

\section{Case Study Results}

The OPP has been working extensively with vendors to develop the integration between their chosen BIM software platform and their existing EAM program. This strategy includes providing visualization of asset information, visibility of owner/operator data requirements, 
and feedback of building performance. The proposed integration workflow, as shown in Figure 3 , includes a central database with a bidirectional link because the model and associated information will be accessed differently for departmental tasks. The goal of this project is to develop a system, working within each of the departments typical workflows, and will be tested and validated on a University Park campus facility.

\section{BIM Data Synchronization and Facility Data Export}

During the initial stages of model creation, the user will be able to export model attributes and data into the EAM system either directly or through IFCs into the EAM system which will be read through the EAM's import application. The EAM system will then create a standardized list of attribute fields for each asset imported. Those fields are then exported back into the modeling software where the appropriate project stakeholder will populate the attribute fields. After all fields are populated by the responsible party and then verified through construction and facility commissioning, the two systems are synchronized allowing both the modeling software and the EAM database to view and modify data in their respective systems. This results in an accurate and up-to-date "as-maintained" model of the facility for use throughout its lifecycle.

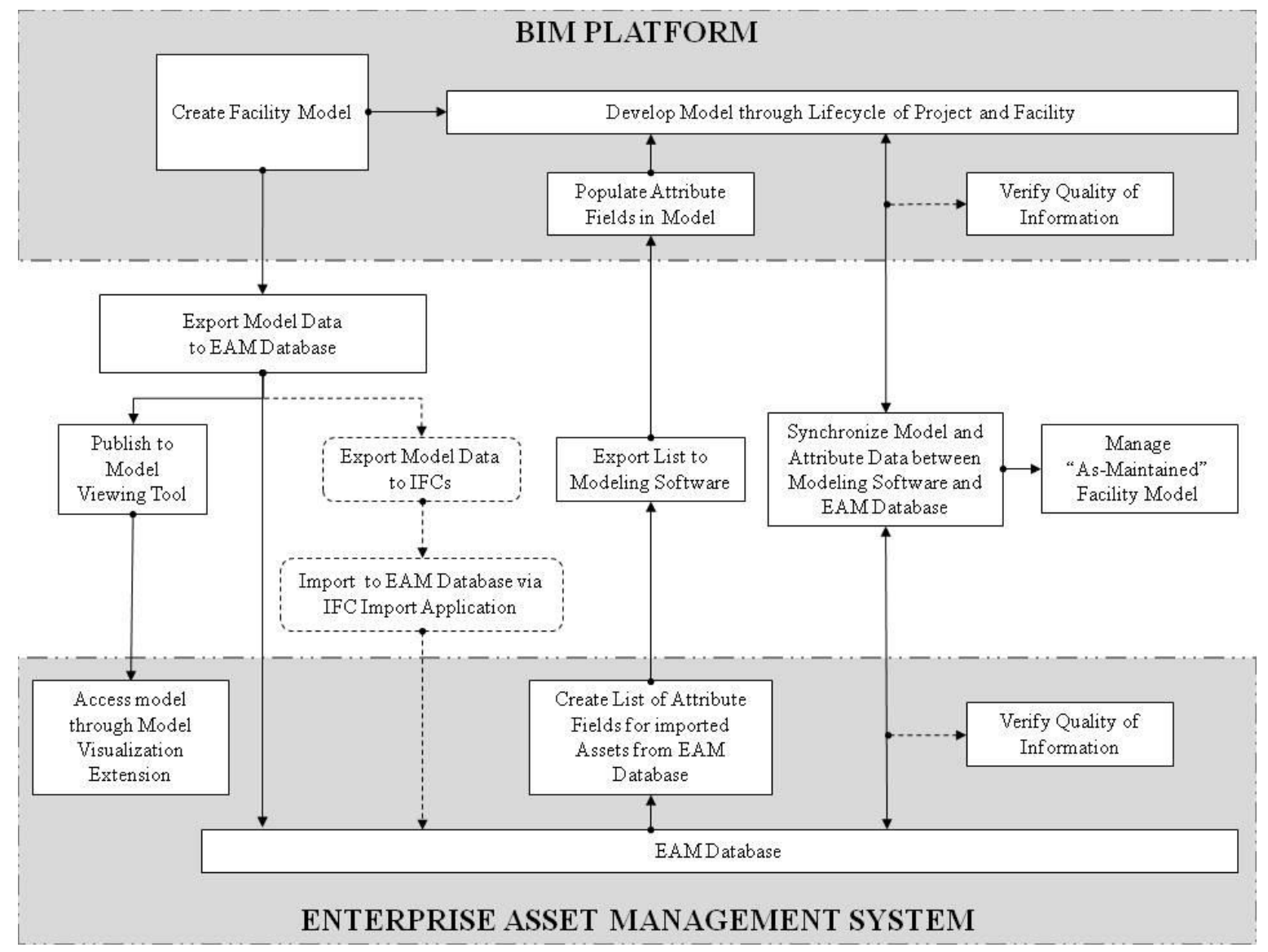

Figure 2 Proposed bilateral workflow from BIM Platform to EAM System

\section{Building Visualization Integration}

Coinciding with model and EAM system integration, an extension within the EAM allows for a maintenance tech to view an asset in 3D. This visualization integration provides the user with geospatial data previously unavailable through a more traditional EAM system. 


\section{Pilot Study}

In order to test the integration process between the BIM platform and CMMS system, the OPP has chosen the Millennium Science Complex (MSC) as a pilot study. MSC, shown in Figure 4, is a 275,000 square foot, $\$ 230$ million state-of-the-art research facility on the PSU University Park campus. The project is scheduled for completion during the summer of 2011. MSC will be the first PSU facility which will employ a full time building engineer and be maintained by a specific operative crew, which allows for maximum control of the data integration process.

During the construction of the MSC project, models were developed for 3D coordination of major components and equipment. However, due to the timing of project turnover as well as the magnitude of the facility, EAM information integration was not contractually required. It was not until the project was approximately seventy-five percent complete that the OPP decided to focus on the development of the BIM platform and the existing EAM program. Therefore, the pilot study that is being developed includes data entry by the contractor, and will give the team a very good idea about the dollar value that can be saved if the EAM information is populated throughout the lifecycle of future projects. The value will be captured on time spent to find, modify, and organize the information based on the aforementioned criteria.

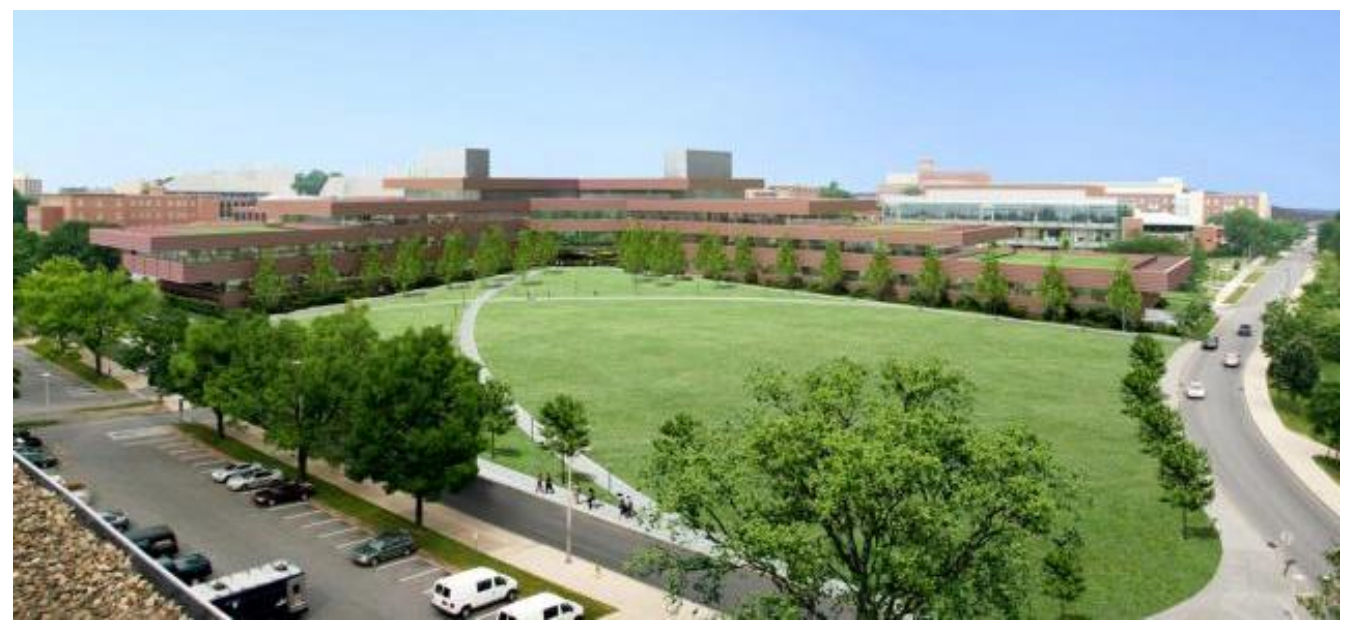

Figure 3 A model rendering of the Millennium Science Complex created by Viñoly Architects

\section{Initial Findings and Challenges}

Through the BIM Project Execution Plan and the OPP Owners BIM Requirements, PSU is in the position to acquire a large amount of relevant data to be located in the EAM central database before commissioning and project turnover. The WCC will then have the ability to have access to this information initially and will only need to field verify asset attributes, rather than spending resources on data acquisition and verification. Having access to this verified data will also allow maintenance personnel to have correct data attribute and performance information when out in the field performing maintenance tasks. The centralized database will contain the O\&M manuals as well as any specific notes relating to the asset. The WCC will also have read-only access to the model and will be able to visualize not only the location of the asset, but the system and area the specific asset effects.

Another important finding during the development was the reverse engineering required to complete the integration. The WCC views assets through a component based hierarchy as opposed to the systems based approach which is used by professionals and contractors. In order for the integration to be successful, it was necessary to break down these assets into a functional hierarchy within both applications and develop standardized naming convention. 
This case study also determined that even though the contractors are willing to focus their efforts to integrate the information requirements of the owner into a facility model, the process needs to begin very early during the construction process. When there is a delay in acquiring these data needs, the contractor loses flexibility for implementing the data retrieval process at the appropriate time and will need to facilitate a data entry process after the fact, ultimately at the cost of the owner and potentially the life of the facility and its assets.

This information accessibility is available to the OPP Design Services as they continue to renovate and design new layouts for existing facilities. The professionals in this group will not only have digital access to the original design data, but access to the maintenance history which will assist in making better informed design decisions. This integration between the initial project stakeholders, the WCC, as well as OPP Design Services on future projects has emphasized the necessity of quality control procedures. These procedures include model and data modification restrictions to only those responsible for the manipulation of information and read-only access to all other users.

\section{Future Work}

There are a few areas of future work that stem from the project case study results. Since this research was exploratory, it required substantial investigation of the information exchange process at the project level. Future research would conclude the integration from the project into facility operations. Specific metrics regarding time and cost savings will be tracked and documented for overall project validation. Additionally, future projects will implement the lessons learned from the MSC project. Specifically, information will be collected throughout the project lifecycle to eliminate a large data exchange at project turnover. Metrics will be collected to investigate any cost incurred by early project participants as well as the increased quality and/or quantity of the information provided to OPP during project turn-over. Penn State is expecting that aligning BIM with facility management procedure will greatly increase both the value of the information provided and total operation efficiency.

Although still in beta form, the BIM to FM integration initiatives implemented by the Office of Physical Plant at The Pennsylvania State University represent an excellent opportunity to identify and develop best practices solutions within the AEC and FM Industries. While the integration between BIM and the existing FM system of the WCC is still in progress, the OPP team has expanded their BIM implementation efforts to include Campus Facility \& Planning, Energy \& Engineering, and Design \& Construction Services. Although these three departments have varying needs and serve different purposes to the University, they were also chosen for their low barrier to entry as well as their high technological competencies.

In order to assist with the complete integration of BIM and developed processes, the OPP is continuing to develop and revise their contract language, as well as implemented an inhouse education strategy. This project's outcome will, in time, continue to support the OPP's effort to implement leaner facility lifecycle strategies and begin to streamline software platforms across all other OPP departments at the University Park campus. The innovative methods delivered by this project should be implemented at the strategic, management, and operational levels by owners with a large catalog of facilities. This will lead to improved facility delivery and lifecycle performance for the benefit of the university community.

\section{Conclusions}

As presented in the NIST study, most owners and operators waste a significant amount of resources yearly on misinformation and information exchange interoperability issues. Because of the magnitude of the facility and asset inventory, PSU is not a typical owner organization and have a set of needs which is much larger than most. However, the OPP can assist industry in developing a recommended work flow for the development of owner

Kasprzak, C and Dubler, C (2012) 'Aligning BIM with FM: streamlining the process for future projects', Australasian Journal of Construction Economics and Building, 12 (4) 68-77 
requirements. In order to improve the operations of any facility, it is important to integrate several different sources of information throughout the project lifecycle, commissioning, and performance analysis (Ballesty 2006). These information requirements need to be realized and then integrated during the early stages of a project lifecycle. While the software platforms may vary between specific projects and owners, developing a collaborative and integrated BIM to FM data exchange solution is necessary for developing a more effective facility design and operations process during the life of a facility. Streamlining the BIM to FM process before project turnover, will enable owners to reduce lifecycle costs and develop more effective operational workflows.

\section{Acknowledgments}

The authors thank colleagues Dr. Edward Gannon and Eric Nulton who provided insight and expertise that greatly assisted the paper. We would also like to acknowledge The Pennsylvania State University's Office of Physical Plant and the Computer Integrated Construction Research Program for supporting this research project. Any opinions, findings, conclusions, or recommendations are those of the authors and do not reflect those of the sponsors or project participants.

\section{References}

Ballesty, S. (2006) 'An Integrated Collaborative Approach for FM-Sydney Opera House Exemplar', Cooperative Research Center for Construction Innovation, Brisbane, Australia

Becerik-Gerber, B., Rice, S. (2010) 'The perceived value of Building Information Modeling in the U.S. Building Industry', ITcon, 15, 185

Bernstein P. and Pittman, J. (2004) 'Barriers to the Adoption of Building Information Modeling in the Building Industry' Autodesk White Paper Retrieved from http://www.ideateinc.com/whitepapers/bim/Revit BIM Barriers to the Adoption of BIM in the Building Industry.pdf

Computer Integrated Construction (CIC) Research Group (2009) 'BIM Project Execution Planning Guide', http://www.engr.psu.edu/ae/cic/bimex/download.aspx (Oct. 9, 2009)

CRC Construction Innovation (2007) Adopting BIM for Facilities Management: Solutions for Managing the Sydney Opera House, Cooperative Research Center for Construction Innovation, Brisbane, Australia

Dubler, C.R., Messner, J., and Anumba, C.J. (2010) 'Using Lean Theory to Identify Waste Associated with Information Exchanges on a Building Project', Proceedings Construction Research Congress / ASCE Conference

Dubler, C.R., Kreider, R., Kasprzak, C., and Messner, J., (2010) 'Project Execution Planning for Building Information Modeling', Construction Industry Institute (CII) Research Summary RES-CPF 2010-1, July, Austin, TX

East, E. William (2010) 'March 2010 COBie Challenge', National Facility Management \& Technology Tradeshow, Baltimore, MD

Gallaher, M. P., O'Connor, A. C., John L. Dettbarn, J., and Gilday, L. T. (2004) 'Cost analysis of inadequate interoperability in the U.S. capital facilities industry', National Institute of Standards and Technology (NIST)

Smith, D. K. (2009) The USC School of Cinematic Arts: The Arrival of Spring in the Facilities Industry', Journal of Building Information Modeling, Spring 2009 